\title{
Comparison of the results of modified NDVI indicator established on the basis of measurements by hyperspectral spectrometer and digital camera
}

\author{
Michał T. Chiliński, Marek Ostrowski \\ Faculty of Biology, University of Warsaw \\ Żwirki i Wigury 105, 02-098 Warsaw, Poland \\ e-mail: mich@igf.fuw.edu.pl
}

\begin{abstract}
Due to the lack of readily available imaging remote sensing methods that would determine the vegetation state on a local scale, an attempt was made to calculate the modified NDVI index on the basis of digital camera photography. To verify the effectiveness of the method, the digital camera and hyperspectral spectrometer results were compared. For the analysis material leaves of six different tree species from an urban area were selected and picked in four different phases of the vegetative season. The results prove that there is no significant correlation between the two methods, but they also suggest that further research on the proposed method is necessary.
\end{abstract}

Key words: remote sensing, vegetation index, local scale, imaging methods

\section{Introduction}

Among the remote sensing methods that are applied for both detection and state assessment of vegetation satellite methods are the leading ones, as they enable to conduct rapid and repetitive broad-space observations, with a great degree of generalization (Rouse et al. 1973). Due to the scale of satellite imaging it is impossible to utilize those methods for local scale environment research, whose subject of detailed analysis are the minute fragments of an ecosystem, undetectable groupings of specimens, or even singular plants, which are sometimes important indicators of the environment characteristics. The lower-level plant groupings, such as those hidden under the tree canopy or ground-level plants of high-growing crops, are also virtually impenetrable for satellite or airplane observations. Only the local scale field methods enable the detection of those objects, their quality, quantity and variability. They also make it possible to observe many other processes, undetectable on a smaller scale (Anderson et al. 2006). The instruments applied for local ground-level remote sensing measurements are dominated by spectrometers (Belyaev et al. 2009), chlorophyll meters (Ruiz-Espinoza et al. 2010) or LAI-meters (Garrigues et al. 2008). These non-imaging apparatuses provide the researchers only with punctual and selective results. Hence, there is a growing need for establishing a methodology for extracting image compositions of NDVI (Compton 1979) indicator of environment condition on the local scale, both directly for research and field research after adaptation. Due to the lack of such remote sensing methods, an attempt was made to measure and represent the local-scale compositions of NDVI indicator on the basis of a digital camera, adapted for near-infrared photography (the anti-IR radiation filter was removed). In the course of the testing procedure a number of analyses were conducted, including a comparison of the NDVI results established for the same objects and using both a digital camera and a specialized hyperspectral spectrometer (Zagajewski et al. 2007). This article aims to present the re- 
sults of the measurements with the application of these two methods, and to draw conclusions from this comparison.

\section{Material}

As the comparative material the leaves of six tree species were used located in environmentally diversified areas of Warsaw. The selected species were: Acer platanoides, Acer pseudoplatanus, Betula pendula, Fagus sylvatica, Quercus robur, Tilia cordata. In different periods of the vegetative season (spring, summer, early and late fall), the leaves, differing in their coloring and expected NDVI indications were extracted. During the first measurement session, seven leaves were extracted from three specimens of each tree species; during each of the following sessions seven leaves were extracted from one specimen of each species. The material was always extracted from the same trees. Overall, 252 samples were used for the analysis, 42 of them for each species. The location of the specimen providing the samples is depicted in Figure 1.

\section{Methods}

A digital camera with a silicon sensor may be utilized as a three-channel imaging detector of 400-700 nm electromagnetic radiation, or, after removing the hot mirror filter blocking near-infrared, for 400-950 $\mathrm{nm}$ radiation. The theoretical spectrum of the digital camera spectral channels over vegetation spectral curve is depicted in Figure 2 (Spivak et al. 2009).

The wavelengths usually applied for establishing the NDVI indicator correspond to the spectrum of red and near-infrared (Carter \& Knapp 2001). As both of those two spectra are encompassed by one camera channel, for the sake of the measurements the near-infrared and 400$500 \mathrm{~nm}$ channel were chosen. Figure 3 presents the chlorophyll absorption of the electromagnetic radiation. This process is present both in the channel utilized for satellite NDVI measurements, and in the modified version proposed for establishing the NDVI via digital photography (Frigaard et al. 1996).

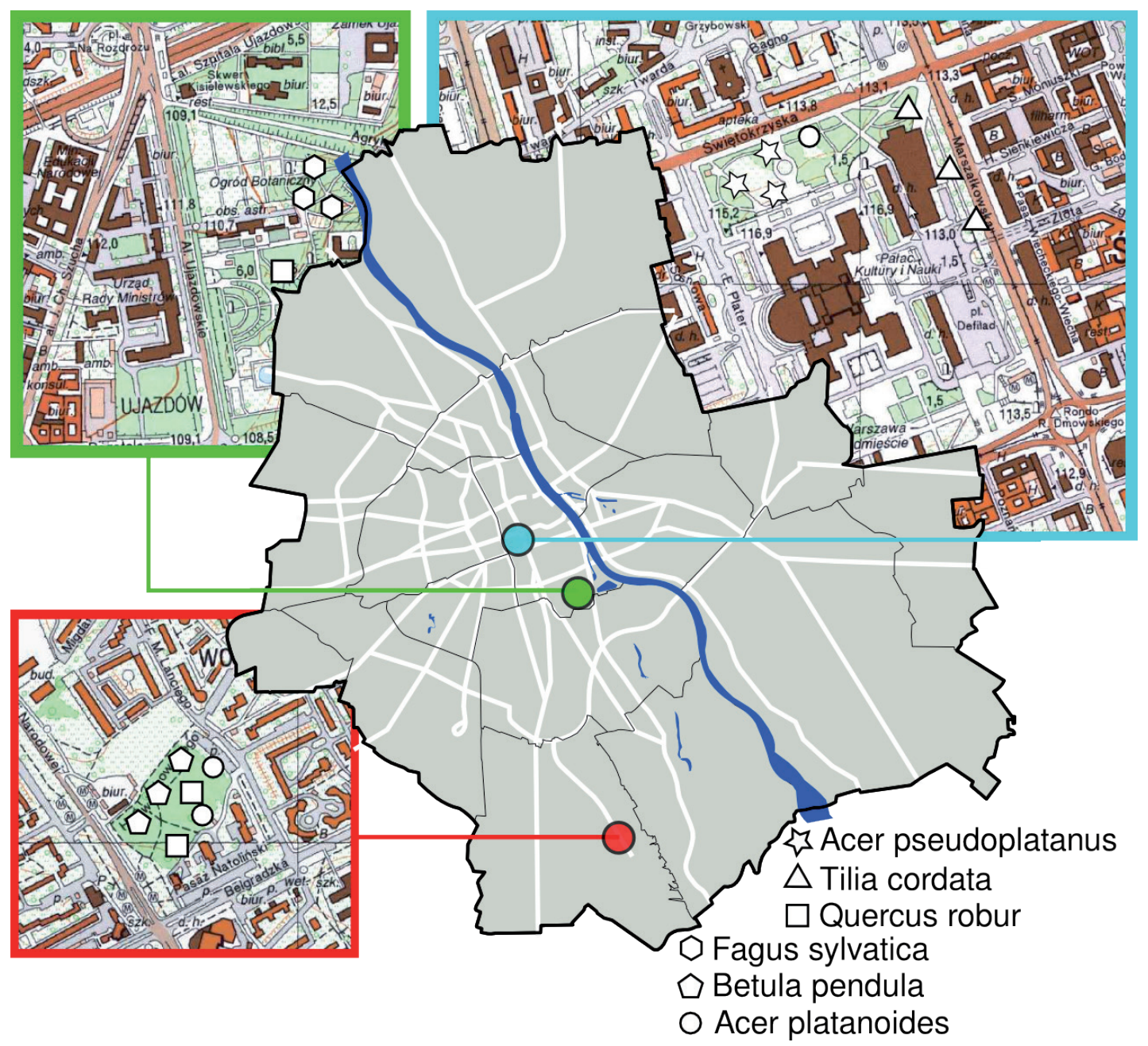

Figure 1. Location of the specimens providing the samples (Warsaw, Poland) 


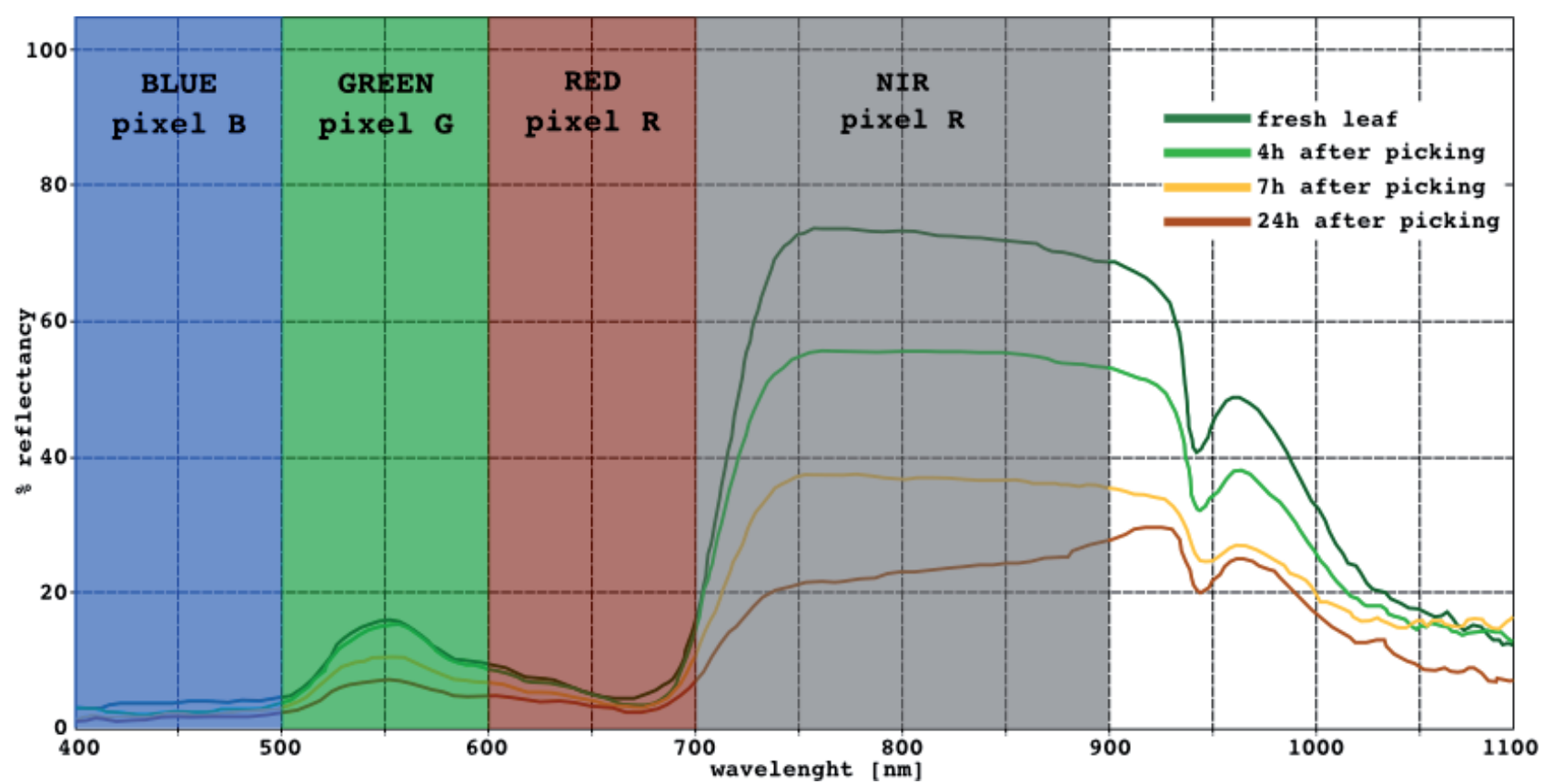

Figure 2. Theoretical spectrum of the digital camera spectral channels over vegetation spectral curve

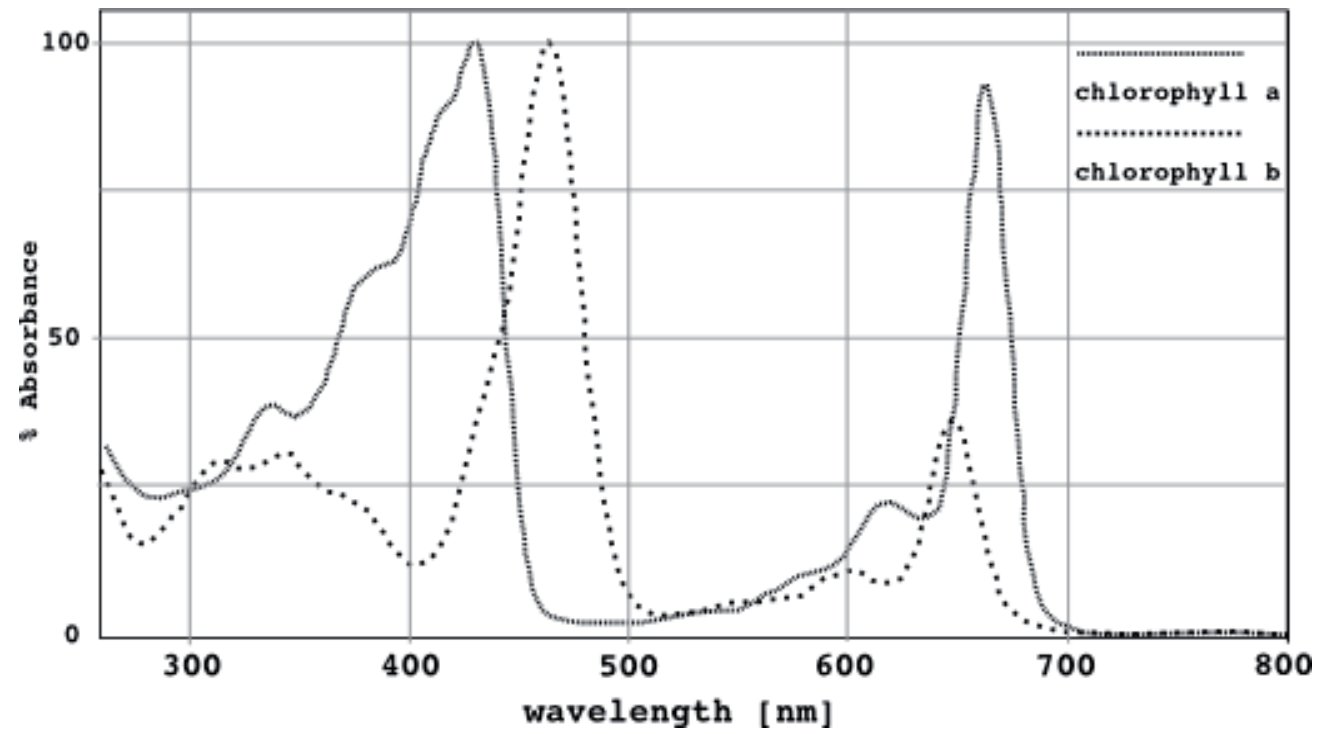

Figure 3. Spectrum of chlorophyll a and chlorophyll $\mathrm{b}$ absorption

The measurements were conducted in laboratory conditions, in artificial light with spectral characteristics similar to the solar spectrum. The sample was exposed to the light of two lamps, standing in relation of 180 degree to each other and in 45-degree relation to the sample. The camera and the optical fiber of the spectrometer were placed opposite each other, and in 90-degree relation to the sample. The ASD Fieldspec 3 spectrometer used offers informa- tion from 2151 channels, with spectrum of 350-2500 nm. Photos and spectrometer measurements were made with a BG-3 chromatic filter, whose characteristics are presented in Figure 4.

The utilized filter cut off the red spectrum of the infrared channel in the digital camera and reduced the spectrum registered by the spectrometer. Seven photos and seven spectrometer measurements of each sample were made 


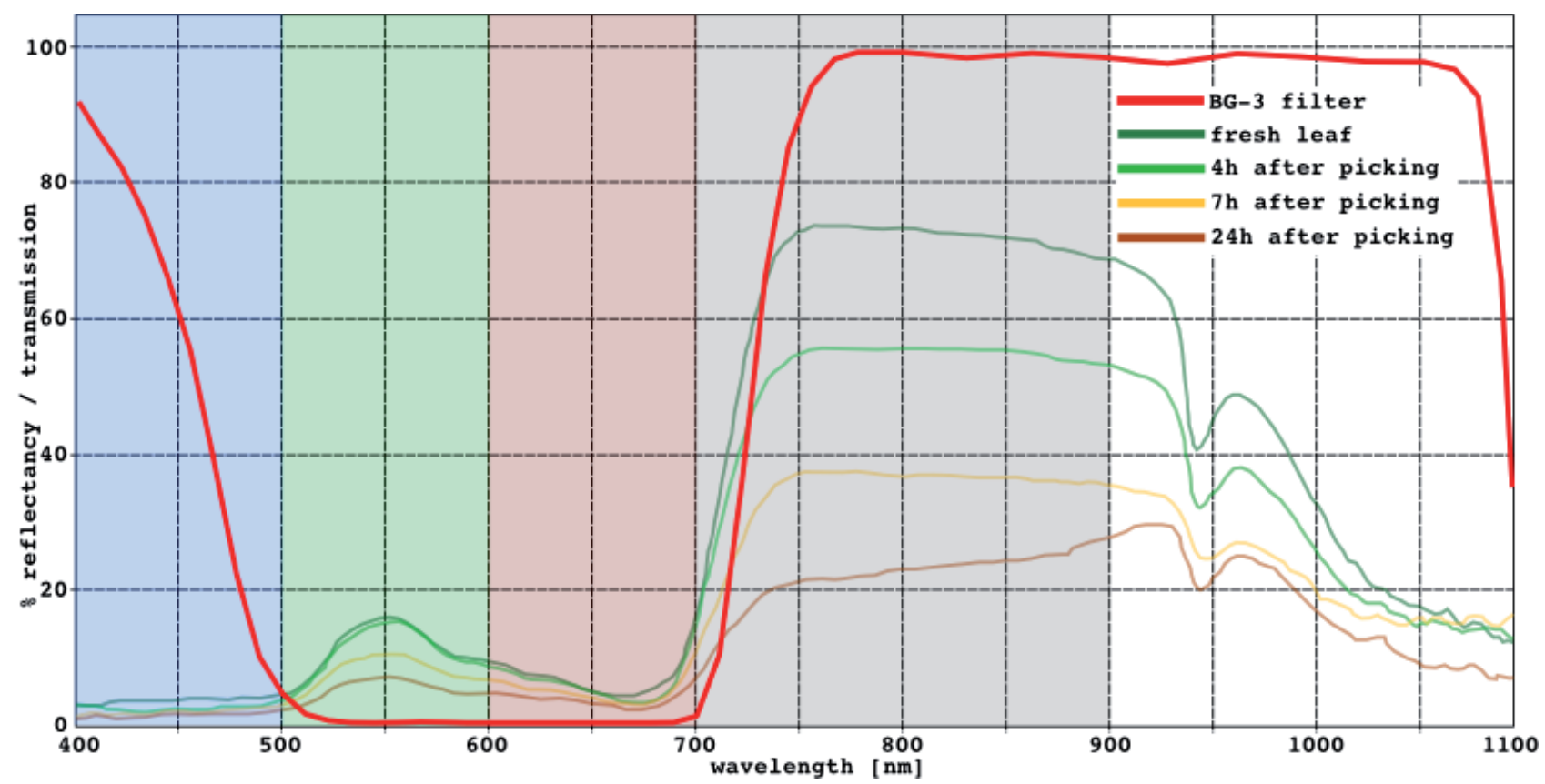

Figure 4. BG-3 filter transmission spectrum over vegetation reflectance spectrum

(the approximation was from twenty readings). The spectrometer measurements were integrated for the spectrum of 400-450 nm and 700-950 nm channels. The main advantage of using a hyperspectral spectrometer for the following comparison is the possibility to integrate the values from the range corresponding precisely to that of the digital camera's spectral sensitivity. In such an approach, a spectrometer device with exactly the same two channels as a digital camera was used. On the basis of the results the NDVI index was established. Digital photos were cropped so as to depict only the sample area, and then they were spatially approximated. In this way, a single value for each sample was established. From the resulting pixel, red and blue channel values were applied for establishing the NDVI index. The pairs of NDVI index values established through measurements of the same sample by two different apparatuses served to establish Spearman's rank correlation coefficient (Spearman 1904). Spearman's rank correlation coefficient is based on the one most popular in environmental studies, Pearson's correlation coefficient (Cornbleet \& Shea 1978), but with ranks instead of real measurement values. Spearman's coefficient does not require any preliminary assumptions, and thus could be used to analyze data with unknown distribution, and it could also detect both linear and non-linear monotonic relationships between the variables. Additionally, it has limited sensitivity for extreme observations. Due to the lack of theoretical description of the relationship between the data from a digital camera and a spectrometer, it was decided to apply the correlation coefficient which has low sensitivity to dataset parameters. That decision led to the choice of using Spearman's rank correlation coefficient. Correlation coefficients were established for all of the results together, and for each of the sessions separately.

\section{Results and Discussion}

Each sample was measured independently seven times, and, additionally, every measurement consisted of 20 consecutive measurements, averaged by the spectrometer and the image processing unit. In total, there were over 70 thousand measurements, 35 thousand for each device. Results for the series per sample were consistent, with an estimated error below $1.5 \%$ of the measured value. This suggests high stability of the measurement setup and sensor. The results differ significantly in the absolute values of NDVI calculated from both spectrometer and digital camera. The NDVI measured with spectrometer was above 0.70 for each season, which corresponds to the values common for vegetation. The digital camera measurements gave significantly lower NDVI values: around 0.20, which means that the camera registered little difference in reflectance between the channels used for NDVI calculation. The detailed results are presented in table 1 which contains: values of the NDVI coefficient measured via both of the methods for each sample, the values of Spearman's rank correlation coefficient for each measurement session, and p-value for the established correlation values. Figure 5 contains a graphic presentation of the results for each measurement session. 

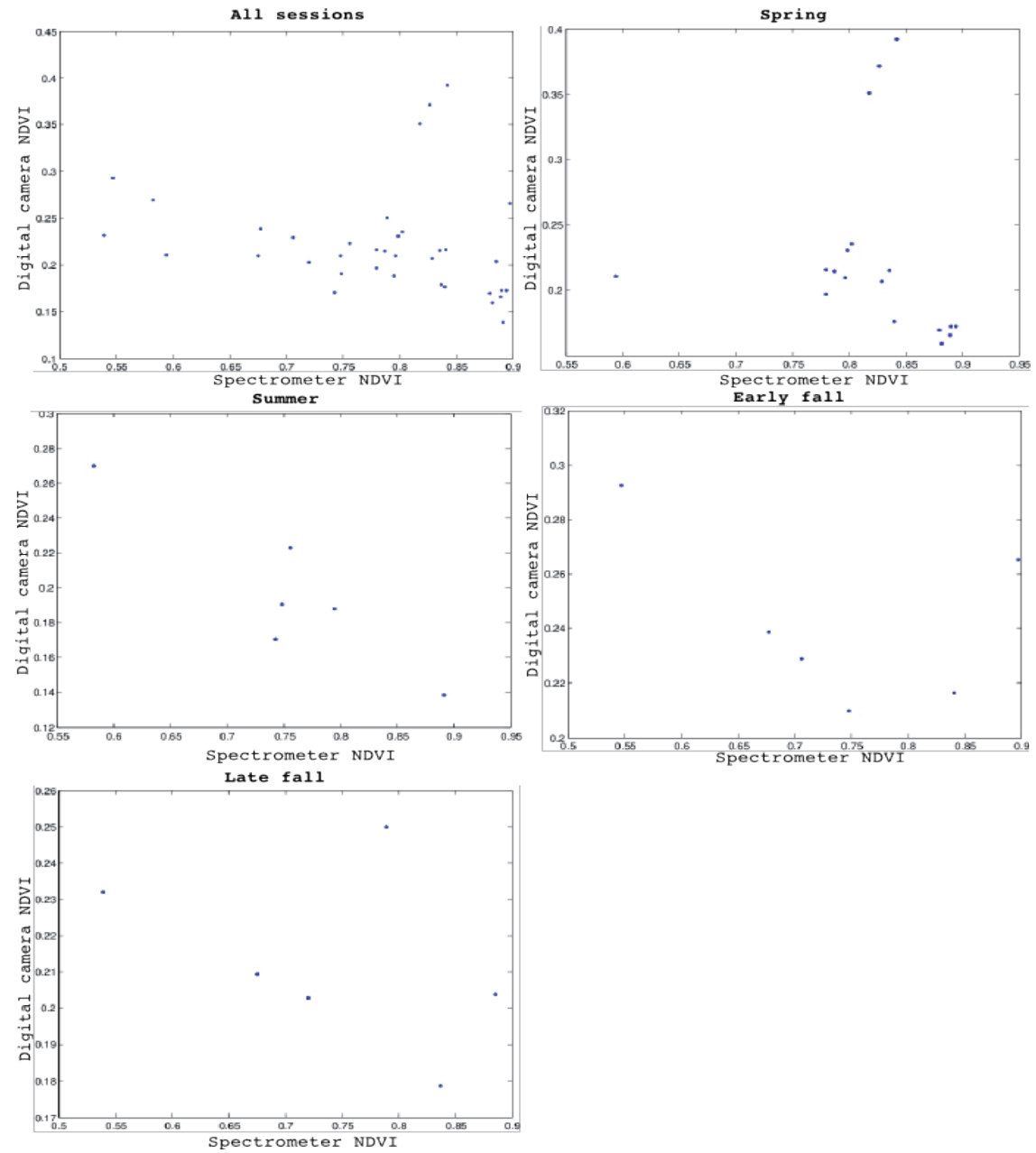

Figure 5. Results of NDVI measured with digital camera and spectrometer in each measurement session

The presented results depict minor seasonal variability of the modified NDVI coefficient $(0.14-0.40$ for the camera, $0.55-0.89$ for the spectrometer) and very low correlation $(\mathrm{R}-0.37--0.60)$ of the measurements between the spectrometer and the digital camera. The correlation coefficient was at minus level, which suggests that the increase of the NDVI value measured with one of the methods corresponds to the decrease of present in the measurements from the application of the other one. The outcome indicates that there is no practical possibility of a comparison of the results of the proposed NDVI coefficient, when differing apparatuses are used. The resulting differences between the two methods may be attributed to the real spectrum difference of the digital camera channels as compared to the spectrum assumed for the experiment. Moreover, at the current stage of the research no complete sensor spectral characteristics of digital camera are available, which is caused by the fact that camera producers consider such information their professional secret. Digital camera photos require approximation to a single result, in order to enable their comparison with the spectrometer results. The whole structure of a leaf (vascular tissue and leaf blade) was visible in the photos, whose singular elements are characterized by different reflectance values. The approximation process required the equal participation of all parts of the leaf. The punctual measurement by the spectrometer might have been dominated by the high-reflectance parts of the leaf, which masked the low-reflectance parts, which caused for the camera-registered values to be lower than the spectrometer-registered ones. 
Table 1. Results of the measurements

\begin{tabular}{|c|c|c|c|c|c|}
\hline Species & Session & Camera NDVI & $\begin{array}{c}\text { Spectrometer } \\
\text { NDVI }\end{array}$ & Correlation (R) & p-value \\
\hline Acer platanoides & spring & 0.24 & 0.80 & $\mathrm{x}$ & $\mathrm{x}$ \\
\hline $\begin{array}{c}\text { Acer } \\
\text { pseudoplatanus }\end{array}$ & spring & 0.21 & 0.59 & $\mathrm{x}$ & $\mathrm{x}$ \\
\hline Betula pendula & spring & 0.22 & 0.84 & $\mathrm{x}$ & $\mathrm{x}$ \\
\hline Fagus sylvatica & spring & 0.17 & 0.89 & $\mathrm{x}$ & $\mathrm{x}$ \\
\hline Quercus robur & spring & 0.22 & 0.78 & $\mathrm{x}$ & $\mathrm{x}$ \\
\hline Tilia cordata & spring & 0.17 & 0.89 & $\mathrm{x}$ & $\mathrm{x}$ \\
\hline $\mathrm{x}$ & spring & $\mathrm{x}$ & $\mathrm{x}$ & -0.5039 & $\begin{array}{c}1.8043^{*} \\
10^{\wedge}-9\end{array}$ \\
\hline Acer platanoides & summer & 0.19 & 0.75 & $\mathrm{x}$ & $\mathrm{x}$ \\
\hline $\begin{array}{c}\text { Acer } \\
\text { pseudoplatanus }\end{array}$ & summer & 0.27 & 0.58 & $\mathrm{x}$ & $\mathrm{x}$ \\
\hline Betula pendula & summer & 0.22 & 0.76 & $\mathrm{x}$ & $\mathrm{x}$ \\
\hline Fagus sylvatica & summer & 0.14 & 0.89 & $\mathrm{x}$ & $\mathrm{x}$ \\
\hline Quercus robur & summer & 0.17 & 0.74 & $\mathrm{x}$ & $\mathrm{x}$ \\
\hline Tilia cordata & summer & 0.19 & 0.80 & $\mathrm{x}$ & $\mathrm{x}$ \\
\hline $\mathrm{x}$ & summer & $\mathrm{x}$ & $\mathrm{x}$ & -0.6000 & $\begin{array}{c}2.6719^{*} \\
10^{\wedge}-5\end{array}$ \\
\hline Acer platanoides & early fall & 0.24 & 0.68 & $\mathrm{x}$ & $\mathrm{x}$ \\
\hline $\begin{array}{c}\text { Acer } \\
\text { pseudoplatanus }\end{array}$ & early fall & 0.29 & 0.55 & $\mathrm{x}$ & $\mathrm{x}$ \\
\hline Betula pendula & early fall & 0.21 & 0.75 & $\mathrm{x}$ & $\mathrm{x}$ \\
\hline Fagus sylvatica & early fall & 0.27 & 0.90 & $\mathrm{x}$ & $\mathrm{x}$ \\
\hline Quercus robur & early fall & 0.23 & 0.71 & $\mathrm{x}$ & $\mathrm{x}$ \\
\hline Tilia cordata & early fall & 0.22 & 0.84 & $\mathrm{x}$ & $\mathrm{x}$ \\
\hline $\mathrm{x}$ & early fall & $\mathrm{x}$ & $\mathrm{x}$ & -0.3714 & 0.0154 \\
\hline Acer platanoides & late fall & 0.25 & 0.79 & $\mathrm{x}$ & $\mathrm{x}$ \\
\hline $\begin{array}{c}\text { Acer } \\
\text { pseudoplatanus }\end{array}$ & late fall & 0.23 & 0.54 & $\mathrm{x}$ & $\mathrm{x}$ \\
\hline Betula pendula & late fall & 0.20 & 0.72 & $\mathrm{x}$ & $\mathrm{x}$ \\
\hline Fagus sylvatica & late fall & 0.20 & 0.89 & $\mathrm{x}$ & $\mathrm{x}$ \\
\hline Quercus robur & late fall & 0.21 & 0.68 & $\mathrm{x}$ & $\mathrm{x}$ \\
\hline Tilia cordata & late fall & 0.18 & 0.84 & $\mathrm{x}$ & $\mathrm{x}$ \\
\hline $\mathrm{x}$ & late fall & $\mathrm{x}$ & $\mathrm{x}$ & -0.4286 & 0.046 \\
\hline
\end{tabular}


Minor seasonal variability indicates that the changes in the plant state have little impact on the value of the coefficient utilizing the near-infrared and blue channels. The proposed NDVI modification does not enable a clear distinction of the plant environment, but only its detection. Chlorophyll decay ought to result in the disappearance of the sample absorption processes in the 400-500 nm spectrum, which does not happen in the course of the experiment. This phenomenon may be caused by radiation absorption by other pigments, which efficiently mask the chlorophyll decay (Solovchenko et al. 2011).

\section{Conclusion}

The experiment enabled the analysis of the applications and possible limitations of digital camera usage for establishing local NDVI indicator, in the future cooperating with satellite images and low-scale NDVI indicators established on their basis. The application of a standard camera of unknown spectrum characteristics for the experiment required the establishing of modified NDVI indicator on the basis of the blue and infrared channels. The digital camera and the hyperspectral spectrometer results of the NDVI indicator differ considerably, and the low minus correlation between them proves that there is no desired relation between them. The proposed modification of the NDVI indicator does not allow for sufficient differentiation of the plant state, as it only allows for its detection.

That does not mean, however, that the direction of the research on simple digital camera sensor application for NDVI (as far as availability and low cost is concerned) is invalid. Conversely, the results indicate the need for further research on the measurement method and for the establishment of plant state indicators on the basis of the full images of the digital photographic sensors. Recent years have brought much new research in the field of the use of digital cameras for assessment of vegetation state. All published papers have in common that their motivation was the desire to decrease the costs of measurement devices and increase spatial resolution of other remote sensing methods. The necessity of improvement in the field of choosing the best vegetation indexes could be found in works on a field of agricultural embedded systems (Sakamoto et al. 2011; Dvorak et al. 2013) and forest monitoring (Sonnentag et al. 2012). Some papers present results of very good correlation between digital camera and spectrometry calculated NDVI, but when every sample was photographed twice with and without a filter, which allows researchers to calculate NDVI from red and NIR channel (Fisher et al. 2011). Further experiments ought to be conducted using a camera of known spectral characteristics of its sensor, so as to enable the selection of an appropriate filter that would make it possible for the NDVI indicator to be established on the basis of channels similar to those generally applied.

\section{References}

Anderson M., Kustas W. \& Norman J. A., 2006, Multiscale remote sensing-based modeling system for estimating local and regional fluxes, AIP Conference Proceedings 852: 146-153.

Belyaev B., Belyaev Y., Katkovskii L. \& Tsikman I., 2009, Estimation and analysis of the parameters of a field spectroradiometer covering the spectral range 350-2500 nm. Journal of Applied Spectroscopy 76 (4): $577-584$.

Carter G. \& Knapp A., 2001, Leaf optical properties in higher plants: linking spectral characteristics to stress and chlorophyll concentration, American Journal of Botany 88 (4): 677-684.

Cornbleet J. \& Shea M., 1978, Comparison of Product Moment and Rank Correlation Coefficients in the Assessment of Laboratory Method-Comparison Data, Clinical Chemistry 24 (6): 857-861.

Compton T., 1979, Red and photographic infrared linear combinations for monitoring vegetation, Remote Sensing of Environment 8 (2): 127-135.

Dworak V., Selbeck J., Dammer K., Hoffmann M., Zarezadeh A. \& Bobda C., 2013, Strategy for the Development of a Smart NDVI Camera System for Outdoor Plant Detection and Agricultural Embedded Systems, Sensors 13 (2): 1523-1538.

Fischer T., Veste M., Eisele A., Bens O., Spyra W. \& Hüttl R., 2012, Small scale spatial heterogeneity of Normalized Difference Vegetation Indices (NDVIs) and hot spots of photosynthesis in biological soil crusts, Flora - Morphology, Distribution, Functional Ecology of Plants 207 (3): 159-167.

Frigaard N., Larsen K. \& Cox R., 1996, Spectrochromatography of photosynthetic pigments as a fingerprinting technique for microbial phototrophs, FEMS Microbiology Ecology 20: 69-77.

Garrigues S., Shabanov N., Swanson K., Morisette J., Baret F. \& Myneni R., 2008, Intercomparison and sensitivity analysis of leaf area index retrievals from lai-2000, accupar, and digital hemispherical photography over croplands, Agricultural and Forest Meteorology 148: 1193-1209.

Rouse J., Haas R., Well J., \& Deering D., 1973, Monitoring vegetation systems in the great plains with erts, [in:] Third Earth Resources Technology Satellite-1 Symposium, Vol. I: Technical Presentations Section A: 309-317.

Ruiz-Espinoza F., Murillo-Amador B., \& Beltran-Morales A., 2010, Field evaluation of the relationship between 
chlorophyll content in basil leaves and a portable chlorophyll meter (spad-502) readings, Journal of Plant Nutrition 33 (3): 423-438.

Sakamoto T., Shibayama M., Kimura A., Takada E., 2011, Assessment of digital camera-derived vegetation indices in quantitative monitoring of seasonal rice growth, ISPRS, Journal of Photogrammetry and Remote Sensing 66 (6): 872-882.

Solovchenko A., Chivkunova O., \& Maslova I., 2011, Pigment composition, optical properties, and resistance to photodamage of the microalga Haematococcus pluvialis cultivated under high light, Russian Journal of Plant Physiology 58 (1): 9-17.

Sonnentag O., Hufkens K., Teshera-Sterne C., Young A., Friedl M., Braswell B., Milliman T., O'Keefe J. \& Richardson A., 2011, Digital repeat photography for phenological research in forest ecosystems, Agricultural and Forest Meteorology 152: 159-177.

Spearman C., 1904, The proof and measurement of association between two things, American Journal of Psychology 15: 72-101.

Spivak A., Belenky A., Fish A. \& Yadid-Pecht O., 2009, Wide-dynamic-range CMOS image sensors - comparative performance analysis, IEEE Transactions on Electron Devices 56 (11): 244-246.

Zagajewski B., Lechnio J. \& Sobczak M., 2007, Wykorzystanie teledetekcji hiper spektralnej w analizie roślinności zanieczyszczonej metalami ciężkimi [Application of imaging spectroscopy in analysis of heavy metals contaminated plants], Teledetekcja Środowiska 37: 82-100. 